\title{
ОСНОВНЫЕ НАПРАВЛЕНИЯ УПРАВЛЕНИЯ И ПОВЫШЕНИЯ ЭФФЕКТИВНОСТИ МЕХАНИЗМА ВНЕШНЕЭКОНОМИЧЕСКИХ СВЯЗЕЙ В ПАРТНЕРСТВЕ ГОСУДАРСТВЕННОГО И ЧАСТНОГО CEKTOPA
}

\author{
Саттарова Хилола Бурхановна \\ Ферганский государственныій университет, \\ г.Фергана, Узбекистан
}

\begin{abstract}
Аннотация. В работе рассматриваются вопросы государственно-частного партнерства как одного из наиболее эффективных способов решения вопросов внешнеэкономических отношений в мире, уделяется внимание реализации инвестиционных проектов на основе государственно-частного партнерства, а также анализируется состояние механизма внешнеэкономических связей в мире и приводятся некоторые рекомендации по решению этих проблем.

Annotation. The work examines the issues of public-private partnership as one of the most effective ways to solve the issues of foreign economic relations in the world, pays attention to the implementation of investment projects based on public-private partnerships, and also analyzes the state of the mechanism of foreign economic relations in the world and provides some recommendations for solving these problems.

Ключевые слова: Государство, частный сектор, инфраструктура, экономические отношения, внешнеэкономические связи, менеджмент, эффективность, инвестиции

Key words: State, private sector, infrastructure, economic relations, foreign economic relations, management, efficiency, investment
\end{abstract}

С первых лет независимости в стране создана правовая база для либерализации всей внешнеэкономической деятельности с целью расширения, развития и стимулирования внешнеэкономических связей республики, а также приняты базовые законодательные акты и создаются условия для их исполнения.

Сегодня из опыта развитых стран, мы видим, что государственно-частное партнерство (ГЧП) играет важную роль в развитии экономики страны и улучшении внешнеэкономических связей. Одна из важных задач - изучить опыт развивающихся стран в этой сфере и внедрить их практику в нашей стране. В частности, особенно важно изучать опыт стран G20 и других развитых и развивающихся стран в сфере государственно-частного партнерства и напрямую внедрять их успешные практики в этой сфере в нашей стране.

Сферы, которые следует учитывать для повышения эффективности внешнеэкономических связей страны это развитие логистической отрасли, создание или модернизация современных предприятий, производство или импорт современных технологий, создание и импорт сырья, подготовка или переподготовка квалифицированных специалистов, отправка персонала на повышение квалификации и навыков. Также основными проблемами являются отсутствие недостаточное количество инвестиций и низкий уровень задействования современных технологий для реализации необходимых инвестиционных проектов по развитию и модернизации этих территорий. Одним из наиболее эффективных способов решения подобных проблем в мире является реализация инвестиционных проектов на основе государственно-частного партнерства.

Действительно, расширение государственно-частного партнерства в развитии современных предприятий это отдельный вопрос. Широкое внедрение такой практики в этой области непосредственно будет содействовать улучшению качества отрасли. В современной рыночной экономике государственно-частное партнерство (ГЧП) является эффективным инструментом экономического и социального развития на национальном и региональном уровнях. Развитие социально-экономической инфраструктуры - один из ключевых факторов, поддерживающих долгосрочный экономический рост любой страны. Недостаточно сформированная инфраструктура препятствует экономическому росту, негативно влияет на качество услуг, предоставляемых населению и гражданам зарубежных стран, снижает интенсивность предпринимательской активности. Именно поэтому, сегодня в мировой практике важную роль играет развитие инфраструктуры страны на основе государственно-частного партнерства.

В мировой практике существуют разные модели, формы, виды и уникальные возможности для реализации государственно-частного партнерства.

Представляет важность развития практики ГЧП в Узбекистане. Ежегодно мир тратит много денег на создание и поддержание инфраструктуры, определяющей благополучие людей. Если мы обратим внимание на цифры и прогнозы, то увидим, что страны мира уделяют этой сфере большое внимание. В мировой практике, особенно в развитых странах, стало доброй традицией инвестировать в развитие инфраструктуры с участием частного сектора. Ожидается, что к 2040 году эта цифра вырастет на 42 процента до 3,7 триллиона долларов (1таблица) [3]. 
Динамика вложенных и ожидаемых инвестиций в улучшение мировой инфраструктуры ${ }^{1}$ (в трлн. долл., прогноз)

\begin{tabular}{|c|c|c|c|c|c|}
\hline Регионы & 2018 & 2025 & 2030 & 2035 & 2040 \\
\hline По всему миру & 2,6 & 2,9 & 3,2 & 3,5 & 3,7 \\
\hline В том числе: & & & & & \\
\hline Азия & 1,5 & 1,7 & 1,9 & 2,1 & 2,3 \\
\hline Северная и Южная Америки & 0,5 & 0,5 & 0,6 & 0,6 & 0,6 \\
\hline Европа & 0,5 & 0,5 & 0,5 & 0,6 & 0,6 \\
\hline Африка & 0,1 & 0,2 & 0,2 & 0,2 & 0,2 \\
\hline
\end{tabular}

Как видно из таблицы 1, вложенные и ожидаемые инвестиции в улучшение мировой инфраструктуры для развития ключевых секторов составило 2,6 трлн. сумов. Из них 49,6\% (1292,8 млрд. долл.) составили прямые инвестиции в транспортный сектор [3]. При этом 32,6\%, 10,5\% и 7,2\% или 1312,7 млрд.сумов соответственно было потрачено на энергоснабжение, информационные и коммуникационные сети и системы водоснабжения. Несмотря на то, что так много материальных средств расходуется на развитие инфраструктуры по всему миру, их все еще недостаточно. В частности, в 2019 году во всем мире цифра на расходы на развитие инфраструктуры достигла 427 миллиардов долларов. К 2040 году, помимо запланированных инвестиций по всему миру, ожидается еще потратить 14 триллионов долларов [2].

Государственно-частное партнерство - это система правовых и институциональных отношений между государственным или местным правительством и частным сектором с целью развития социально важных и слаборазвитых секторов национальной экономики для защиты общественных интересов. Основы этой системы будут основаны на равенстве, рациональном сотрудничестве, справедливом распределении рисков и выгод, а также на сочетании усилий государственного и частного секторов.

Согласно исследованию «The Global Infrastructure Hub», изучающему инфраструктурные рынки развитых и развивающихся стран, к 2030 году ожидается, что объем инвестиций в развитие внешнеэкономической деятельности по сравнению с 2018 годом увеличится на 26\% или на 3,3 трлн. долларов. Или в 2040 году эта цифра достигнет 3,813 трлн.долл.

В исследованиях, проведенных «The Global Infrastructure Hub», публикуются прогнозы инвестиций в инфраструктуру и финансовых средств, необходимых для будущего в странах по всему миру (2-таблица).

Таблица 2

Объем мировых инвестиций в ключевые сектора инфраструктуры ${ }^{2}$ (в млрд. долл., прогноз)

\begin{tabular}{|c|c|c|c|c|}
\hline Сферы инфраструктуры & 2018 г. & В \% к общему & 2030 г. & 2040 г. \\
\hline Транспорт & 1292,8 & $49,6 \%$ & 1664,2 & 1943,7 \\
\hline Энергетика & 850,3 & $32,6 \%$ & 1060,5 & 1232,8 \\
\hline Информация-коммуникация & 273,6 & $10,5 \%$ & 319,1 & 359,2 \\
\hline Водоснабжение & 188,8 & $7,2 \%$ & 236,4 & 277,1 \\
\hline Всего: & 2605,5 & $100 \%$ & 3280,20 & 3812,80 \\
\hline
\end{tabular}

Таблица 2 показывает, что инвестирование в высококачественную инфраструктуру положительно влияет на основной экономический рост и на внешнеэкономическую деятельность каждой из стран, создание рабочих мест и увеличение налогооблагаемого дохода [3].

Такие организации, как Исследовательский институт Азиатского банка развития (ADBI), проводят исследования, для определения положительных результатов, которых можно достичь за счет создания качественной инфраструктуры.

1 Ю.Хусаинов. “Жить с верой в будущее - высочайшее счастье” // Экономический вестник Узбекистана, №3, 2018г., c.40-42

${ }^{2}$ Ю.Хусаинов. “Жить с верой в будущее - высочайшее счастье” // Экономический вестник Узбекистана, №3, 2018г., с.40-42 
Итак, в результате открытия железной дороги Ташгузар-Байсун-Кумкурган в Узбекистане темп роста ВВП по региону составил $2 \%, 5 \%$ в промышленности и $7 \%$ в сфере услуг.

В современных условиях развития экономических отношений в нашей стране на основе рыночных законов достижение устойчивой внешнеэкономической деятельности является важным условием обеспечения макроэкономического роста. Сегодня необходимо провести практическую работу по стимулированию внешнеэкономической деятельности, увеличению экспортного потенциала страны и усилению производства экспортно-ориентированной продукции, особенно по разработке импортозамещающей продукции с целью увеличения участия и достижения эффективной внешнеэкономической деятельности регионов.

По мнению экспертов, к концу 2021 года этап индустриального развития мировой экономики подойдет к концу. Это приведёт к резкому увеличению объема информации, необходимой для разработки и принятия управленческих решений в макроэкономике. В результате умения и навыки сотрудников, а также уровень развития информационных и коммуникационных технологий в каждой стране определяют ее развитие и конкурентоспособность. Ожидается, что цифровая экономика приведет к беспрецедентным изменениям более чем в половине существующих секторов. В частности, исследование экспертов Всемирного банка показало, что увеличение числа пользователей высокоскоростного интернета на $10 \%$ только позволит национальной экономике расти на $0,4-1,4 \%$ ежегодно. Темпы роста «цифровой экономики» в мире достигли уже почти $20 \%$ в год. В развитых странах доля «цифровой экономики» в ВВП достигла 7\%. Они уже получают большие выгоды от ее внедрения в экономику.

В частности, Соединенные Штаты ежегодно экспортируют «цифровые услуги» на сумму более 400 миллиардов долларов. Сегодня более 5\% ВВП страны приходится на Интернет, информационные и телекоммуникационные технологии. К 2025 году США получат дополнительно 20 трлн. долларов от «оцифровки» промышленности. Такая экономическая эффективность особенно высока в производстве потребительских товаров (10,3 трлн.долл.), автомобильной промышленности (3,8 трлн.долл.) и логистике (3,9 трлн.долл).

В Узбекистане также уделяется большое внимание внедрению «цифровой экономики». Государственная программа по реализации Стратегии действий по пяти приоритетным направлениям развития Республики Узбекистан на 2017-2021 годы в 2018 году - «Год активного предпринимательства, поддержки инновационных идей и технологий» включает «Умный город», «Умная махалля», «Умный дом» и «Умный хокимият» [2]. Планируется разработать комплекс нормативно-правовых документов.

Концепцию «умного города» планируется реализовать в столице нашей страны, а также в центре Ташкентской области - Нурафшане.

$\mathrm{B}$ сотрудничестве с Программой развития ООН разработан проект «Умное сельское хозяйство» для Янгиюльского, Орта-Чирчикского, Паркентского и Ташкентского районов Ташкентской области.

В связи с этим необходимо реализовать государственную приоритетную политику, связанную с опорой на местное сырье и ресурсы, разработать комплекс программ по повышению эффективности системы экспорта продукции отечественного производства и внешнеторговой инфраструктуры [4].

Необходимо отметить, что кризисный фактор в 2020 году, имеющий иной характер от долгового кризиса, изначально не приобретавший экономический характер, является пандемией. В результате чего появляются некоторые сигналы экономического коллапса. Главный из них - наступление «экономических каникул». Другими словами, это напрямую связано со снижением совокупного потребления и прекращением совокупного предложения. Главный симптом этого экономического кризиса - экономическая бездеятельность. В этом контексте основной задачей государства должно быть обеспечение минимальной экономической активности.

В настоящее время это также способствует обострению конкуренции на международной арене, усилению борьбы каждой страны за укрепление своих позиций в международном разделении труда, обеспечение его стабильности.

Государственно-частное партнерство следует признать не только фактором, определяющим уровень развития социально-культурной сферы и инфраструктуры, но и одной из особых опор, которые выведут развитие экономики и внешнеэкономической деятельности страны на новый уровень.

Необходимо разработать прозрачную и справедливую систему создания базы данных государственночастного партнерства в ближайшем будущем, формирования и систематического анализа их с открытыми, реальными данными, создания системы обучения для проектов ГЧП, определения последовательной работы по дальнейшему развитию инфраструктуры и социальной сферы, главное, в выборе государственного партнера. При реализации государственно-частного партнерства необходимо контролировать следующие моменты:

- информация о стоимости текущих проектов, сроках реализации, особенностях, информация о частном партнере должна быть предоставлена прозрачно;

- государственное агентство по развитию частного партнерства при Министерстве финансов Республики Узбекистан должно стать уполномоченным органом в сфере государственно-частного партнерства для отслеживания текущих инфраструктурных проектов в стране, определения источников финансирования; 
- в качестве институциональной основы для координации отношений ГЧП необходимо разработать и реализовать меры по недопущению монополии частных инвесторов на реализацию инвестиционных проектов.

- необходимо разработать отдельную государственную программу, чтобы наша страна имела индекс QI (Quality Infrastructure), который определяет уровень развития инфраструктуры стран на международном уровне [7].

В нашей стране тоже следует обратить особое внимание на вопросы предоставления свободы местным публичным властям с участием государственного сектора в государственно-частном партнерстве, развитию государственно-частного партнерства с местными инвесторами на региональном уровне. При разработке механизма государственно-частного партнерства на региональном уровне необходимо обратить внимание на следующие аспекты:

Во-первых, установить правовые механизмы партнерства органов местного публичного управления и частных инвесторов;

Во-вторых, разработать механизм поощрения местных инвесторов к участию в проектах по развитию инфраструктуры (посредством налогов, финансовых стимулов, специальных прав и т. д.) и тем самым повысить интерес частных инвесторов к участию в проектах ГЧП;

В-третьих, Агентству ГЧП при Министерстве финансов необходимо систематизировать показатели уровня ГЧП при реализации инфраструктурных проектов в регионах, и в этой связи определить рейтинг регионов, введение годового индекса (Ri) ГЧП проектов в регионах, необходимо определить дальнейшие перспективы оценки и улучшения региональной инфраструктуры.

Это будет способствовать развитию рынка проектов ГЧП в Узбекистане, а также формированию здоровой конкуренции между государственным и частным секторами (местными инвесторами) и, в конечном итоге, поднятию уровня внешнеэкономической деятельности нашей страны до международного уровня.

\section{Список литературы:}

1. Послание Президента Республики Узбекистан Ш.Мирзиёева Олий Мажлису // uza.uz // Национальное информационное агентство Узбекистана 25.01.2020 Версия для печати.

2. Государственная программа «О реализации Стратегии действий по пяти приоритетным направлениям развития Республики Узбекистан на 2017-2021 годы в «Год активного предпринимательства, поддержки инновационных идей и технологий ». // Сайт Национального информационного агентства Узбекистана (УзА) www.uza.uz.

3. Ю.Хусаинов. “Жить с верой в будущее - высочайшее счастье” // Экономический вестник Узбекистана, №3, 2018 г., c. $40-42$

4. Olimova, N.X., \& Axunova, O.E. (2020). Evaluation of the investment environment of fergana region and investment activity of real sector enterprises in it. // Новые информационные технологии как основа эффективного инновационного развития (рр. 102-109).

5. Олимова, Н.Х., \& Ахунова, О.Э. (2020). Способы эффективного развития инвестиционной деятельности предприятий реального сектора. Архивариус, $(7$ (52)).

6. Олимова, Н.X. (2019). Роль свободных экономических зон в развивающихся странах и анализ привлеченных инвестиций в их экономическое развитие. // Тенденции развития мировой торговли в XXI веке. (рр. 349-354).

7. Эргашев, А.Х. (2019). Приоритетные направления повышения роли инвестиций в реализации и модернизации комплексной программы промышленного развития страны. // Тенденции развития мировой торговли в XXI веке. (рp. 424-427).

8. Эргашев, А.Х., \& Уринбаева, Д.Х. (2019). Анализ использования маркетинговых стратегий в организации и конкурентоспособности маркетинговой деятельности. // Тенденции развития мировой торговли в XXI веке. (pp.123-131). 